\title{
Spin-offs of the Third Mission and social innovation: the case study of the research-training-intervention project of Geodata $\mathrm{Ltd}^{1}$
}

\author{
Ezio Del Gottardo ${ }^{\mathrm{a}}$, Salvatore Patera ${ }^{\mathrm{b}}$ \\ ${ }^{a}$ Università telematica Pegaso, Italy, edelgottardo@gmail.com,0000-0002-5214-7755 \\ ${ }^{b}$ University of Salento, Italy, toto.patera@gmail.com,0000-0002-1201-5328
}

\begin{abstract}
As a result of enactment of Law 297/1999, many Italian universities could improve the opportunities in applied research, activating spin-offs and start-ups in conformity with those regulations. This is a new challenge in the universities' mission: universities are capable (and therefore they are asked) to generate not only new knowledge and competent professional profiles, but also to make a new effort in implementing the "third mission" for promoting social innovation. Considering this background, we present a research project - a training intervention named "Participatory culture, personal branding and organisational wellness" - by Espéro Pvt, a spin-off of the University of Salento, for Geodata Engineering Ltd., located in Turin, Italy. Presented below are the theoretical framework (learning organisation, empowerment evaluation and organisational wellness) and the methodology, as well as the first results.
\end{abstract}

Keywords: Third mission, social innovation, learning organisation, empowerment evaluation, organizational communication

\section{Academy and enterprise: third mission (public engagement), quintuple helix and social innovation}

"Public engagement" expresses the concept of the third mission of universities. Anvur (2013) says "Public engagement describes all the educational, cultural, and social development non-profit activities". This infuses a new definition to the universities' mission: universities are able and therefore they are asked to generate not only new knowledge and competent professional profiles but also to make a new effort in implementing the "third mission".

Considering this background, in compliance with the principles of the quintuple helix model, the third mission aims to encourage relationships among universities, industry, government and the community, to promote sustainability in terms of products and processes (Carayannis and Campbell, 2010).

This commitment responds therefore to two fundamental demands: participation and change.

The first is the ability to build new strategies and orientations to spread knowledge in society through communicative and management processes, including engagement, fundraising and citizens' participation.

The second requirement is training and learning; universities are directly responsible for social change. This second requirement might be wrongly read as a "technical simplification": social change meant just as a diffusion of techniques, methods and relative products (rights) in a merely "functionalist" perspective; social change just as the answer to social and professional duties. This vision would be limiting or even counterproductive.

The first priority in university policies is to create the right conditions for each individual to fully express his/her own potential, consciously contributing to social development as a whole. For this reason, universities' third mission should always have, besides the "public engagement" characteristic, that of "community empowerment" (Table 1).

\footnotetext{
${ }^{1}$ This article has been produced jointly by the two authors; however, the final drafting of paragraphs can be attributed as follows. Del Gottardo: "Academy and enterprise: third mission (public engagement), quintuple helix and social innovation"; "Research-training-intervention project: "Participatory culture, personal branding and organisational wellness", the case study of Geodata Ltd."; "Conclusions". Patera has contributed "Methodology".
} 


\section{Spin-offs of the Third Mission and social innovation: the case study of the research-training-intervention project of Geodata Ltd \\ Del Gottardo, Patera}

Table 1 - Differences between public engagement and community empowerment

\begin{tabular}{ll}
\hline Public engagement & Community empowerment \\
\hline $\begin{array}{l}\text { Scope: creation of products and services (public goods) that } \\
\text { increase social wellness }\end{array}$ & $\begin{array}{l}\text { Scope: enhancement of the territory through sharing and co- } \\
\text { production of socially and culturally relevant knowledge, with effects } \\
\text { not necessarily and primarily economic }\end{array}$ \\
$\begin{array}{l}\text { Objective: sharing of university didactics and research } \\
\text { benefits with the territory }\end{array}$ & Objective: starting sustainable processes of local development \\
$\begin{array}{l}\text { Actions: widespread, cognitive: territory and community share } \\
\text { the final widespread stage and implement products and }\end{array}$ & $\begin{array}{l}\text { Actions: identifying and involving territory and community in the } \\
\text { decision-making process. Path of double communication } \\
\begin{array}{l}\text { Visions: university informs the territory of the scientific } \\
\text { research results; territory and community are competitive } \\
\text { areas }\end{array}\end{array} \quad \begin{array}{l}\text { Visions: university helps by giving guidance to the territory as a } \\
\text { social change maker. Territory and community are partners and } \\
\text { decision-makers }\end{array}$ \\
\hline
\end{tabular}

Following the concept of "community empowerment", we introduce a research-training-intervention project named "Participatory culture, personal branding and organisational wellness", by Espero Pvt., Ltd., a spin-off of the University of Salento, for Geodata Engineering Ltd., a company located in Turin, Italy. This project was possible largely due to the enactment of Law 297/1999, by which many Italian Universities could improve the opportunities in applied research, activating spin-offs and start-ups.

In this sense, following social innovation literature (Murray, et al., 2010), this project focusses on complex adaptive systems, collaborative approaches and innovation diffusion. At the same time, the project improves the aspects of social innovation reported in "Rediscovering social innovation" (Phills et al., 2008).

\section{Research-training-intervention project: "Participatory culture, personal branding and organisational wellness", the case study of Geodata Ltd.}

\subsection{General objective}

The scope of work was an evaluative research on the company employees' training needs and company managements social needs, in terms of transversal competencies that should be acquired to enhance awareness and mutual understanding and co-build a shared model of organisational change. This is in compliance with what is prescribed in the "Documento aziendale di valutazione lavoro-stress correlato" (Document of work environment-related stress evaluation), which is part of the security pack as per Italian Law (D.Lgs 81/2008 and D.Lgs 106/2009).

\subsection{The context}

The project was executed at Geodata Engineering Ltd., Turin, Italy, a global leader in subsoil and territorial engineering.

\subsection{Theoretical framework}

The project considers organisational wellness as "all those cultural nuclei, all processes and organisational practices that activate coexistence dynamics in the work environment and promote, maintain, and foster quality of life and physical, psychological and social wellness in the work community" (Avallone and Bonaretti, 2003, p. 13).

Organisations can generate wellness, or they may not, depending on the definition of work environment and of some practices, and they can also have a direct influence on the entire health system. Organisational wellness lies in the quality of the relations between the people and the work environment. An organisation that wants to improve and is able to both understand social problems in context and adopt relevant strategies of intervention embraces the logic of Learning organisation (Argyris, 1999). Moreover, the theoretical and methodological model of the project is that of Empowerment evaluation, whose main function is to enable defining relevant innovations, as well as fostering and supporting in all participants awareness and a self-determination process. This approach aims to help organisations interiorising evaluative principles and practices to consciously cope with problems, to define objectives and find solutions and - as a stimulus - to always revise the project they are working on (Fetterman, 1994, p. 15).

\subsection{Methodology}

Following the mandate of Geodata Ltd., formalised during the first meeting, it was decided that the scope of the research could be that of providing useful evaluative and planning knowledge, to both the employees and the company managers, to share a" participatory culture in the workplace", which could reduce the risks derived from the work 


\section{Spin-offs of the Third Mission and social innovation: the case study of the research-training-intervention project of Geodata Ltd \\ Del Gottardo, Patera}

environment-related stress and, at the same time, improve organisational wellness in the branch of Geodata Ltd. in Turin (Whitmore, 1998; Guba, Lincoln, 1989; Stake, 1980).

The research objective is primarily that of beginning an evaluative research project on work environment-related stress to draft the document of "evaluation of work environment-related stress", in compliance with current norms. Starting from the results of this evaluative research, we conducted a training in the company, addressed to all actors involved (managers and employees), with the educational objective of improving organisational wellness in the workplace, with reference to problems that emerged from the evaluation phase. In the constructive evaluation framework (learning evaluation) (Scriven, 2007), these requirements were expressed in terms of social needs by the managers and the employees; they were read and reformulated under the sub-category of educational needs. On the basis of the educational needs, we planned and implemented training sessions to improve awareness and ability of both the managers and the employees so as to reduce the risks derived from work environment-related stress and, at the same time, to improve organisational wellness in the company (Reason, 2001).

At the end of the training sessions, in terms of intervention objectives, we implemented shared evaluation/planning activities addressed to all actors involved, with the aim of co-producing visions and shared actions, and therefore shared changes that both parties would think necessary to reduce the risks derived from work environment-related stress and to improve organisational wellness in the company.

The project was executed in 3 macro phases as follows:

1. Research project: In this macro phase, we mapped the social problems as per the customer's indications. W prepared a focussed interview for the Chairman of Geodata Ltd. The focussed interview (Ferrarotti, 1998) was restricted to 2 themes: perceptions of organisational wellness and work environment-related stress. Starting from the analysis of the interview, we could formulate the ustomer's social needs (1.1). Results were presented to the customer as a method to reflect and gain awareness regarding the project process considering the 2 mentioned themes (1.2). A first version of the project "alpha" (1.3) was presented, and subsequently, the contract was signed and the project started (1.4). The evaluative research on work environment-related stress (1.5) took place and was structured on a policies analysis framework on the topic of the project: D.Lgs 81/2008 and D.Lgs 106/2009 - (1.5.1). Then, we conducted a desk analysis of the company's organisational documents for the previous 3 years, in particular, risk assessment document, and the training provided for managers and employees (1.5.2). Subsequently, we conducted an organisational analysis on secondary data for the managers/employees based on 2 dimensions (personal data and organisation chart), with 4 variables for each dimension for the past three years (1.5.3). After obtaining the results of the preliminary analysis, we conducted an ethnographic research in the company, in particular, in Turin. We used an observation checklist on 1 dimension, Organisational risk, with 7 indicators. This checklist was adapted from related literature on the topic (Wallace, et al. 1999; Riordan, et al. 2005; Reichers, et al. 1990). This ethnographic survey of the context was implemented incognito with only the customer's approval, for a total of 4 meetings of 3 hours each over a period of 3 months. (1.5.4). After this first stage of evaluative research, the team decided to recalibrate the project "beta" (1.6). The project based on this recalibration and on the results of the first surveys was formally presented to the employees and the management team through a process of educational activation, which is meant for sharing the project phases and goals with respect of the topic of research-training-intervention and for the creation of a learning group that considers managers/employees (1.7). The definition of the analysis plan focussed on the explorative dimension of organisational wellness. Through a process of operationalisation, 15 indicators and 30 items were identified. The indicators are:

- Role in the organisation

- Objectives, functions

- Planning of duties

- Workload/rate of work

- Decisional/control autonomy

- Career prospects

- Sense of belonging

- Self-motivation

- Personal satisfaction

- Personal expectations

- Interpersonal relations

- Organisational culture

- Work premises and equipment

- Security

- Comfort

The target group for the survey was composed of 170 subjects (managers/employees) of Geodata (Turin). Contextualising the tools in the organisational training literature (Alessandrini, 2005), we validated the Perceived Organisational Wellness Questionnaire (1.8). The questionnaire used to collect the survey on Geodata employees' training needs was a semi-structured one. It had an initial part, where employees' profiles were anonymously collected, 
and a second part with 30 questions with 15 indicators as shown in Table 2 . The analysis of the internal consistency aims to verify the common part in all items (item homogeneity). The pretest involved 23 people in total. With the purpose of measuring its reliability, we used Cronbach's $\alpha(\alpha$ if deleted, min. $\operatorname{Var}(x)=0.9792 ;-\alpha$ if deleted, max. $\operatorname{Var}(x)=0.9793)$. Moreover, we calculated Spearman-Brown reliability index $(\alpha$ value $>0.90)$. The questionnaire was then given to Geodata employees/managers (1.9) and was available from 23/10/2012 to 30/10/2012; employees could fill it themselves anonymously in a reserved area. All compilers' data were codified and linked, in addition to being treated anonymously on the basis of current regulations on this matter. We then conducted a multivariate analysis (ACM) on the data of the Perceived Organisational Wellness Questionnaire for managers/employees (1.10), and the report on the questionnaire surveys, which includes the initial vision of employees/managers on organisational wellness in Geodata Ltd. (Vision 0), was delivered (1.11);

2. Training project: "Vision 0" on company organisational wellness (managers/employees) illustrated the initial frame of the company with reference to the 15 indicators of organisational wellness. Starting from this first picture, trainings were organised for both the employees and the managers through reflective settings on "Vision 0" data expressed by the survey target (2.1). These reflective settings helped in obtaining a reflection on what emerged from "Vision 0" and a conjoint comparison of employees/managers following the principles of dialogical, constructivist and propositional communication. Employees' and managers' opinions were collected on the basis of what emerged from the reflective settings through a deliberative focus group on the 15 dimensions of the questionnaire, in particular, on those more critical in terms of organisational risk. This was done to define and cluster a shared vision of employees/managers on the organisational wellness (Vision 1) (2.2). What emerged from the deliberative focus group was analysed (2.3) and delivered first to the managers and then to the employees involved in the project (2.4);

3. Intervention project: Following the trainings to reconfigure the individual "Vision 0 " of managers/employees in a new "Vision 1" negotiated and shared by managers/employees, we created a mixed workgroup of managers/employees that, due to the technique of fixed priority scale, defined together spaces for improvement to foster organisational wellness in the company and consequently to reduce the correlated organisational risk (Vision 2) (3.1).

We then wrote the final report and the "Documento di Valutazione dello stress ambiente-lavoro correlato" "Document of work environment-related stress evaluation" (3.2), which was delivered to the customer. Finally, we administered a customer questionnaireon the actions undertaken in the project (3.3).

After the analytic description referred to in the 3 macro phases, we presented the operationalisation in 18 micro phases of the 3 macro phases as presented in Table 2 .

Table 2 - Project's macro phases and micro phases

\begin{tabular}{|c|c|c|}
\hline $\mathrm{N}$ & Activities & Timing \\
\hline 1 & Research problem & $09-2012$ \\
\hline 1.1 & Customer analysis (Geodata Ltd.) & \\
\hline 1.2 & Report on customer analysis & \\
\hline 1.3 & Draft of the project of research-training-intervention (version alpha) & \\
\hline 1.4 & Agreement and project inception & \\
\hline 1.5 & Evaluative research on work environment-related stress & \\
\hline 1.5 .1 & Analysis of policies on project topic & \\
\hline 1.5 .2 & Desk analysis on company documentation & \\
\hline 1.5 .3 & Analysis of company secondary data & \\
\hline 1.5 .4 & Ethno-exploration of the context & \\
\hline 1.6 & Recalibration of the research-training-intervention process (version beta) & \\
\hline 1.7 & Education implementation of the project & \\
\hline 1.8 & Analysis, definition and creation of the Perceived Organisational Wellness Questionnaire & \\
\hline 1.9 & Administering of on the Perceived Organisational Wellness Questionnaire & \\
\hline 1.10 & Multivariate analysis of the Perceived Organisational Wellness Questionnaire & \\
\hline 1.11 & Delivery of the results of the Perceived Organisational Wellness Questionnaire (Vision 0) & \\
\hline 2 & Training project & $02-2013$ \\
\hline 2.1 & Training on Vision 0 & \\
\hline 2.2 & Deliberative focus group with employees/managers to define and cluster Vision 1 & \\
\hline 2.3 & Deliberative focus group data analysis (Vision1) & \\
\hline 2.4 & Delivery of report with Vision 1 with the employees/managers & \\
\hline 3 & Intervention project & 04-2013 \\
\hline 3.1 & Fixed priority scale with mixed groups of employees/managers to define the areas of improvement (Vision 2) & \\
\hline 3.2 & Final report draft and "Documento di Valutazione dello stress ambiente-lavoro correlato"” & \\
\hline 3.3 & Design of customer satisfaction tool on approval rating and its delivery to employees/managers & \\
\hline
\end{tabular}

\subsection{Results for each of the three macro phases}

1. Research project: Customer analysis report (1.1), based on the surveys collected in the focussed interview with the Chairman of Geodata Ltd., gave us a view on the following: a) perceptions on organisational wellness and 2) perceptions on work environment-related stress in Geodata Ltd. There was awareness regarding different requirements that need to be mapped to reduce and limit work environment-related stress and to enhance company organisational 


\section{Spin-offs of the Third Mission and social innovation: the case study of the research-training-intervention project of Geodata Ltd \\ Del Gottardo, Patera}

wellness. This is a challenge for the company in terms of reflective ability in identifying potential critical requirements that could lead to "organisational risk", to reduce them through training sections that allow sharing and negotiating of the different points of view towards a shared objective. When the Chairman (1.2) expressed this social need (Senge and Sterman, 1992), we could reformulate the matter in reflective terms with the aim of defining enhancing strategies and thereby designing the research project of research-training-intervention in its first version "alpha" (1.3) and (1.4). Policy analysis, starting from the research results with evaluative scope on work environment-related stress (1.5), highlighted the importance of evaluating in a shared way as much as possible both workplace environmental characteristics (material component) and the quality of the relational climate (immaterial component); the latter is often spoiled due to diverse factors (1.5.1). The desk analysis of the company's organisational documentation of the previous three years (company risk assessment and trainings for managers/employees) actually highlighted some risk factors (1.5.2), which are supported by the results that emerged and also by the data of the ethno-exploration in the company, in particular in the new branch in Turin. Desk analysis results and 12 hours of observation through the checklist on the Organisational Risk dimension (with 7 indicators) showed a generally positive framework, particularly when referring to the item of the indicator "Prevention of Accidents and Professional Risks". Although the organisational risks evaluated in the past three years before the implementation of the project seemed to have been reduced, there were some risk factors that could be elaborated in terms of research-training-intervention with respect to the social need that emerged in Report 1.1 of the company (1.5.4). In particular, it is advisable to deepen the analysis on the following:

The need to have more clarity regarding organisational objectives and their consistency with the organisational performances put in practice (high priority):

a) The need to map employees' competencies to value and enhance them (high priority)

b) The advisability of improving circular intra-organisational communication, "who does what" (middle priority)

Starting from this, we implemented an organisational analysis on secondary data for managers/Employees on two dimensions (personal data and organisation chart), with 4 variables for each dimension, in the past three years (1.5.3). The company's growth in the previous years was highlighted by the fact that the number of employees with less than 5 years of service in Geodata was $40 \%$, while $36 \%$ are subjects with more than 10 years of service and just $24 \%$ comprised subjects with number of years of service ranging between 6 and 9. Following the recalibration of the research-training-intervention project (version beta) (1.6), as well as the educational activation project for the concerned employees (1.7), the analysis plan focussed on the explorative dimension of organisational wellness was designed, with 15 indicators and 30 items (Table 1). The semi-structured questionnaire on perceived organisational wellness (1.8) and(1.9) was elaborated on this basis, with answering option on Likert scale with 4 scores and 3 open questions. The "Vision 0" of managers/employees was derived from the questionnaire surveys that were delivered to the customer: (1.10) and (1.11). With reference to the structural dimension of work premises, subjects' judgement was widely positive for the indicators of "comfort", "workplace and equipment", "security" (for e.g. privacy, personal space availability, etc.). The more significant factors (assumed from the indicators in Table 1) were primarily the "enhancement of competencies" and a better "internal communication", as well as the need for a better "operational smoothness". In fact, apart from the positive indicators $(13,14$ and 15), the other indicators with the highest positive score were "sense of belonging" (7) and workload/rate of work (4). The most critical ones, always in an acceptable organisational risk level but which would deserve to be elaborated in terms of diagnosis and prevention, were "Planning of duties" (3), "Career prospects" (6), "Personal motivation" (8) and "Organisational culture" (12);

2. Training project: "Vision 0", which we derived from the Perceived Organisational Wellness Questionnaire shows that the Company is doing well; nevertheless, it has to focus on some aspects and some areas of improvement. When diagnosed, these areas can be prevented, organisational risks can be reduced and wellness in the workplace can be maintained. The reflective settings (2.1) helped the employees and the managers to focus and gain awareness on some points, in particular the following: the evaluation is useful to progressively "regulate" the interventions, so that they respond to the specific situational needs and can direct the training. This awareness (Hakkarainen, et al, 2004) yields some results for each indicator of organisational wellness and can reduce organisational risks of work environmentrelated stress as well as improve organisational wellness levels. The evaluation allows starting pertinent actions, i.e. responding to contextual needs; efficiency, i.e. steps consistent with the objectives, and effectiveness, which can have the desired effects and meet the needs of the people who are involved. The managers/employees focus group (2.2), starting from the results in "Vision 0", helped in redefining and clustering all shared aspects after consultation and negotiation among the diverse perspectives to define a "Vision 1"; in particular (2.3), regarding managers and employees (Vision 1), this is the framework that emerged (Table 3). 


\section{Spin-offs of the Third Mission and social innovation: the case study of the research-training-intervention project of Geodata Ltd \\ Del Gottardo, Patera}

Table 3 - Vision 1 Employees/managers

Employees
- Prevention of burn-out and psychological disturbances related to the job, due to
an improvement of internal communication regarding "assignment of duties"

an improvement of internal communication regarding "assignment of duties"

Managers

- Reduction of indirect costs due to employees' demotivation and burn-out

- Improvement of internal communication, intra- and inter-services regarding the company duty organisation, which needs to be clearer and more shared.

- Strengthening of the sense of belonging in the work team and in the company, due to ongoing training of reflective type to orientate the company's "organisational culture" taking into account the different ages/years of service in such a dynamic and growing company

- Strengthening of the professional identity through mapping and enhancing the competencies to improve "Personal motivation" and "Career prospects" in the

- Strengthening of the sense of belonging and of the collaboration levels as a result of periodical meetings on team building

- Introduction of tools to map employees' competencies so as to reduce the costs derived from the externalisation of services.

3. Intervention project: The delivering of the results in "Vision 1" (2.4) created the bases to jointly define intervention strategies (Vision 2) to improve the company context. In particular, the Fixed Priority Scale with mixed groups of employees/managers (3.1) indicates some operational priorities to improve the company's organisational wellness and to reduce organisational risks, which can increase the levels of work environment-related stress in the company.

Communication field:

1. Developing an intra-organisational, horizontal/vertical communication system; Employees field:

1. Developing a grid of employees' competencies;

2. Implementing a system for evaluation and enhancing of working performances;

Development field:

1. Implementing a standardised system of the working processes aimed at developing a project;

2. Designing a system of Knowledge Management.

\section{Conclusions}

With reference to the "Documento di Valutazione dello stress ambiente-lavoro correlato" (3.2) delivered to the customer, the company status is good and there is a low level of work environment-related stress. Despite this, because some critical points were detected in the previous 3 years' data, it is advisable to improve research and interventions to identify organisational risk factors on time and to put in place interventions to prevent/reduce those organisational risks and the consequent work environment-related stress.

The entire evaluation process served the purpose of being educational, because it was meant to redirect and improve the organisation and also because it aimed to empower the actors, giving them tools to gain awareness, selfdetermination, sense of responsibility and professional skills.

The more important educational effect in terms of "organisational innovation" is having understood that the evaluation is a constant and ongoing need, to have continuous and updated communication-information-interaction flows, which are the humus for all the social actors in an organisation.

The main research and intervention activities were designed to be supported by information and communications technology (ICT) platforms for organisational learning aided by the mixing of digital tools (Google, Drive Survey Monkey, etc.) both on desktops and on mobile media. The "beta" version of the platform was designed to support the process of research and intervention in the company, taking into account that learning processes require technological infrastructure to support the production and exchange of knowledge (Senge, 1990).

The beta version of this proposal contains the following: research-intervention repository of outputs; company's tutorials; open data on training and professional development; and database of assessment tools.

From this point of view, it is important to set up a learning environment that interacts with the corporate work environment in the direction of promoting a "community of continuous learners" for professional development and onthe-job training (Pedler, et al.; 1989). Furthermore, the beta version of the digital platform is aimed at both enhancing personal learning environments and developing practitioners to be lifelong learners (Mackeracher, 2004; Dlabach, 2015). In particular, the beta version is designed for the purpose of supporting data-informed decisions and increasing employee engagement to make company communication more effective and, at the same time, inspiring collaboration and sharing attitudes within the company. 
Del Gottardo, Patera

\section{References}

Alessandrini, G. (Ed.) (2005). Formazione e sviluppo organizzativo. Roma: Carocci

Anvur (2013). La Terza Missione nelle Università e negli enti di ricerca italiani. Documento di lavoro sugli indicatori.

Argyris, C. (1999). On Organizational Learning. Massachusetts: Blackwell Publishers Inc.

Avallone, F. \& Bonaretti, M. (2003). Benessere organizzativo. Per migliorare la qualità del lavoro nelle amministrazioni pubbliche. Roma: Rubbettino

Carayannis, E. G., \& Campbell, D. F. J. (2010). Triple Helix, Quadruple Helix and Quintuple Helix and how do knowledge, innovation and the environment relate to each other? A proposed framework for a trans-disciplinary analysis of sustainable development and social ecology. International Journal of Social Ecology and Sustainable Development, 1(1), 41-69

Dlabach, G., (2015). The Life Cycle of the Digital Learning Organization. Journal of Education and Human Development. Vol. 4, No. 2(1), pp. 246-247

D. Lgs. 3/8/2008, n. 106 "Disposizioni integrative e correttive del decreto legislativo del 9 aprile 2008, n. 81 in materia di tutela della salute e della sicurezza nei luoghi di lavoro"

D. Lgs. 9/4/2008, n. 81, "Attuazione dell'art. 1 legge 3 agosto 2007, n. 123 in materia di tutela della salute e della sicurezza nei luoghi di lavoro"

D. Lgs. 27/5/1999, n. 297 "Riordino della disciplina e snellimento delle procedure per il sostegno della ricerca scientifica e tecnologica, per la diffusione delle tecnologie, per la mobilità dei ricercatori”

Ferrarotti, F. (1998). Manuale di sociologia. Roma: Laterza

Fetterman, D. M. (1994). Empowerment Evaluation, Evaluation Practice, 15 (1), pp. 1 - 15

Guba, E. G. \& Lincoln, Y. S. (1989). Fourth Generation Evaluation. Sage: Newbury Park

Hakkarainen, K., Palonen, T., Paavola, S. \& Lehtinen, E. (2004). Communities of networked expertise: Professional and educational perspectives. Amsterdam: Elsevier

Mackeracher, D. (2004). Making Sense of Adult Learning, $\mathrm{II}^{\circ}$ Edition. Toronto: University of Toronto Press

Murray, R., Caulier-Grice J., \& Mulgan, G. (2010). The Open Book of Social Innovation. The Young Foundation and NESTA

Nussbaum, M. C. (2002). Giustizia sociale e dignità umana. Da individui a persone. Bologna: Il Mulino

Pedler, M., T, Boydell, and Burgoyne, J. (1989) Towards the learning company, Management Education and Development, 20, 1-8

Phills Jr., J. A., Deiglmeier, K., \& Miller, D. T. (2008). Rediscovering Social Innovation. Stanford Social Innovation Review: Fall

Reason, P. (2001). Learning and change through action-research. In Henry J., (Ed.) Creative Management. London: Sage Publications

Reichers, A. E., \& Schneider, B. (1990). Climate and culture: An evolution of constructs. In B. Schneider (Ed.), Organizational climate and culture. San Francisco: Jossey-Bass

Riordan C.M., Vandmberg R. J., \& Richardson H.A., (2005). Employee involvement climate and organizational effectiveness. Human resource Management, 44, (4), pp. 471-488.

Scriven, M. (2007). The logic of evaluation. In H.V. Hansen, et. al. (Eds), Dissensus and the Search for Common Ground, (pp. 1-16). Windsor, ON: OSSA

Senge, M. (1990). The leader's new work: Building learning organizations, Sloan Management Review, Fall, 7-23

Senge, P. M., \& Sterman, J. D. (1992). Systems Thinking and Organizational Learning: Acting Locally and Thinking Globally in the Organization of the Future. In. Kochan, T. A \& Useem M. (Eds.). Transforming Organizations. New York: Oxford University Press

Stake, R. E. (1980). Program Evaluation, Particularly Responsive Evaluation. In Dockrell, W. B. \& Hamilton, D. (Eds.). Rethinking Educational Research. London: Hodder and Stoughton

Wallace J., Hunt J., \& Richard C., (1999). The relationship between organisational culture, organisational climate and managersial values. International Journal of Public Sector Management, 12, (7), pp. 548-564

Whitmore, E., (1998). Understanding and Practicing Participatory Evaluation. New Directions for Evaluation, n. 80, San Francisco: Jossey-Bass 